\title{
Correction to: Deflationism About Logic
}

\section{Christopher Blake-Turner ${ }^{1}$}

Published online: 22 November 2019

(C) Springer Nature B.V. 2019

\section{Correction to: J Philos Logic https://doi.org/10.1007/s10992-019-09529-5}

The version of this article that was originally published online unfortunately contains mistakes introduced by the publisher during the production process. The version of record that now appears online, as well as the print version of the article, have been corrected. The mistakes which were introduced occurred on the second page of Section 2. Corrections are described in the following list:

1) " $\Delta P$ " on the line which begins "For (ii), let" should instead read " $\mathrm{P} \rightarrow \Delta \mathrm{P}$ "

2) " $P \vdash_{S V} P \rightarrow \Delta P$ " on the line which begins "To show that $S V$ fails" should read "P $\vdash_{S V} \Delta P$ "

The online version of the original article can be found at https://doi.org/10.1007/s10992-019-09529-5

Christopher Blake-Turner

chrisbt@live.unc.edu

1 Philosophy Department, University of North Carolina at Chapel Hill, Caldwell Hall, 240 East Cameron Ave, Chapel Hill, NC 27599, USA 